\title{
Discurso, ideologia e ensino na contemporaneidade: a Escola como lugar (e não-lugar) de interpretação urbana e social
}

\author{
Leandro Siqueira Palcha* \\ Odisséa Boaventura de Oliveira**
}

\section{Resumo}

Este estudo investiga seis diários de estágio produzidos por licenciandos do Curso de Ciências Biológicas que descrevem as observações realizadas sobre uma Escola Pública e tem por objetivo observar como os mecanismos ideológicos que se confrontam no espaço escolar emergem nessas descrições. Para isso, aproximamos a Escola da Cidade, analisando o entrelaçamento entre o mundo do ensino e a realidade dos sujeitos a partir da Análise de Discurso, em especial os conceitos de Ideologia, de Discurso Urbano e dos conceitos antropológicos de Lugar (espaço em que há relação entre identitário, relacional e histórico) e Não-Lugar (ilustrado pela relação de distanciamento). Observamos que os estagiários apontam a Escola em meio a uma crise de lugar identitário, relacional e histórico. Crise em que as noções de lugar e não-lugar coexistem no mesmo espaço, ao mesmo tempo. Destaca-se que na produção do conhecimento escolar e na formação de professores não se pode pensar em práticas, mas em práxis (ações históricas, dialógicas e dialéticas), concebendo a Escola como espaço multifacetado, produtor de discursos e ideologias, em que as provisoriedades, os conflitos, as pluralidades, crises e rupturas se entrecruzam.

Palavras-chave: Escola. Interpretação. Formação de Professores.

\footnotetext{
* Mestre e Doutorando em Educação pela Universidade Federal do Paraná (UFPR). Professor do Departamento de Ciências Sociais e Humanas da Universidade Federal do Paraná (UFPR), Setor Palotina.

** Doutora em Educação pela Universidade de São Paulo (USP). Professora do Departamento de Teoria e Prática de Ensino e do Programa de Pós-Graduação em Educação da Universidade Federal do Paraná (UFPR).
} 


\section{Introdução}

Inúmeros estudos têm procurado articular o processo de ensino e aprendizagem ao referencial teórico e metodológico da Análise de Discurso (AD) formulada na França por Michel Pêcheux (2002, 2012) e trabalhada no Brasil, principalmente, pelos estudos de Eni Orlandi (1996, 2006, 2012a, 2012b), o que tem oferecido contribuições para pensar a historicidade que permeia a dimensão socioeducativa e também para problematizar o conhecimento científico nas mediações escolares.

Nesses estudos, têm-se colocado em suspensão maneiras naturalizadas de pensar a Escola a partir de conceitos centrais da AD, como o de "discurso" e de "ideologia". O primeiro é compreendido como "efeito de sentidos entre locutores" e ideologia concebida por uma "transparência da linguagem" (ORLANDI, 2013) que apaga a historicidade e as relações que constituem o discurso. Assim, tratar um discurso analiticamente implica desconstruir a transparência significante de suas condições de produção e estabelecer as relações entre o dito e o não dito.

Na mesma direção teórica, problematizamos a Escola, dentro do contexto contemporâneo, como espaço de hibridização de discursos socioculturais, examinando-a como mundo reprodutor e transformador de sentidos, bem como pelo processamento da socialização e não socialização de determinados conhecimentos. Nesse espaço se constituem encadeamentos discursivos e ideológicos que nos indicam outras possibilidades de analisá-la, por exemplo, pela discursividade escolar e urbana que permeia a prática escolar.

Procuramos, então, aproximar a Escola da Cidade, espaço em que há disputa e/ou aliança entre as instâncias administrativas que visam manter a ordem pública e os movimentos sociais, que podem ser refratários e/ou solidários a esse controle; espaço que abriga o discurso administrado (o ordinário) e o discurso urbano constituído pelos habitantes da Cidade.

O discurso do urbano, para nós, é o discurso constituído a partir da sobreposição do conhecimento urbano sobre a própria realidade da cidade. Nessa indistinção, aquilo que seria a realidade urbana é substituída pelas categorias do saber urbano, seja em sua forma erudita (discurso do urbanista), seja no modo do senso comum em que esse discurso é incorporado pela política, pelo administrador, pela comunidade, convertendo sentidos no imaginário urbano. (ORLANDI, 2004, p. 68).

Compreender a circulação de discursos urbanos na/sobre a Escola implica falar da crise de significados sociais pela qual ela passa na contemporaneidade, em discutir o confronto entre a unidade 
e a pluralidade, em falar de "mundos e não do mundo, mas sabendo que um deles está em comunicação com os outros, que cada um possui pelo menos imagens dos outros" (AUGÉ, 1997, p. 141).

Nessa perspectiva, buscamos discutir o conceito de "contemporâneo", remetendo à ideia de pluralidade dos mundos, de hibridização de discursos e das ideologias que produzem diversos efeitos de sentidos sobre essa realidade. Discursos sobre tecnologias, globalização, consumismo e inclusão, por exemplo, merecem ser analisados para entender os efeitos de sentidos produzidos no ensino.

Para tanto, apresentamos neste artigo parte de um estudo desenvolvido na disciplina Prática de Docência do curso de Licenciatura em Ciências Biológicas, com objetivo de observar e analisar como os mecanismos ideológicos que se confrontam no espaço escolar emergem nas descrições, que os Licenciandos fazem em seus diários de estágio, sobre uma Escola Pública localizada no centro de Curitiba.

\section{Articulação teórica para compreender o discurso, a ideologia e a Escola na contemporaneidade}

Em nossa perspectiva teórica concebemos o contexto escolar como um espaço de interpretação histórica, social e ideológica que mobiliza uma complexidade de relações simbólicas. Neste espaço, em nome da homogeneidade de conservação da estrutura social e do domínio do capital simbólico (BOURDIEU, 2013), as variáveis culturais se apagam. E aí, portanto, reside o paradoxo atual da instituição escolar na medida em que ela serve para socializar um conhecimento legitimado e para não socializar outro.

Para detalhar essa interpretação sobre a Escola, destacamos que o efeito da ideologia afeta o indivíduo em sujeito, pelo seu reconhecimento em uma "forma-sujeito", ao mesmo tempo livre e assujeitada por direitos e deveres (PÊCHEUX, 2009). A ideologia, dessa maneira, comporta um conjunto de representações, lutas e posições de classe, uma vez que:

[...] em sua materialidade concreta, a instância ideológica existe sob a forma de formações ideológicas (referidas aos aparelhos ideológicos do estado) que ao mesmo tempo, possuem caráter regional e comportam posições de classe: os "objetos" ideológicos são sempre fornecidos ao mesmo tempo que a "maneira de servir deles" seu "sentido", isto é, sua orientação, ou seja, os interesses de classe aos quais eles servem -, o que se pode comentar dizendo que as ideologias práticas são práticas de classes (de lutas de classes) na Ideologia. (PÊCHEUX, 2009, p. 132). 
Por outros termos, as formações ideológicas comportariam as subordinações e resistências das estruturas político-sociais, já que as ideologias (práticas) são lutas contra as relações de produção. Elas abarcam certa construtividade de sentidos, porém, a liberdade de produção de sentidos não é plenamente conquistada pelos sujeitos, pois todo dizer já se encontra ancorado ideologicamente e aprisionado discursivamente na memória dos sujeitos, na relação com as instâncias institucionais. Portanto, “o sentido não existe em si, mas é determinado pelas posições ideológicas colocadas em jogo no processo sócio-histórico em que as palavras são produzidas. As palavras mudam de sentido segundo as posições daqueles que as empregam" (ORLANDI, 2013, p. 42).

No encadeamento de uma formação ideológica as formações discursivas se constituem como matrizes dos dizeres e das tomadas de posição do sujeito, à medida que uma "formação discursiva se define como aquilo que numa formação ideológica dada - ou seja, a partir de uma posição dada em uma conjuntura sócio-histórica dada, determina o que pode e deve ser dito" (ORLANDI, 2013, p. 44). A produção de sentidos, então, é resultado da inscrição dos sujeitos em formações discursivas, de uma dada formação ideológica. Metaforicamente falando, significa pensar a formação discursiva como uma "etiqueta" (de comportamento, de posição, de tomada do dizer) dentro de um contexto social e histórico determinado.

A prática simbólica, assim pensada, é marcada por formações ideológicas e discursivas em uma dada conjuntura sociocultural, por onde, sem haver um conhecimento das relações de reprodução, a interpretação da realidade é, em geral, tomada pelo efeito da evidência, em que o dizer/sentido se naturaliza como sendo aquele. Conforme observa Orlandi (2013, p. 45-46):

O fato mesmo da interpretação, ou melhor, o fato de que não há sentido sem interpretação, atesta a presença da ideologia. Não há sentido sem interpretação e, além disso, diante de qualquer objeto simbólico o homem é levado a interpretar, colocandose diante da questão o que isso quer dizer? Nesse movimento de interpretação o sentido aparece-nos como evidência, como se ele estivesse já sempre lá. Interpreta-se ao mesmo tempo nega-se a interpretação, colocando-a no grau zero. Naturaliza-se o que é produzido na relação do histórico e do simbólico.

Desse modo, a ideologia não assume o entendimento de ocultação de ideias circulantes na sociedade, mas produz efeitos de uma automatização delas ao ignorar o processo histórico, apagar a história praticada e renunciar a outras formas de interpretá-las. Nessa medida, o discurso aparece em uma relação indissociável com a ideologia, pelos esquecimentos da história e pela naturalização de uma evidência que imputa outras explicações da realidade. 
A partir dessas considerações, concebemos a Escola como um lugar onde circulam diferentes discursos, ideologias e interpretações, ou seja, um espaço-mundo de sentidos socioculturais. Como uma instituição do Estado, pensamo-la enquanto um local de permanências, mudanças e resistências, ou seja, na perspectiva pecheutiana designamos a Escola como um espaço político-social, tal qual "surge o imprevisível contínuo, porque cada ritual ideológico continuamente se depara com rejeições e atos falhos de todos os tipos que interrompem a perpetuação das reproduções” (PÊCHEUX, 2009, p.115).

Portanto, é um local onde há reprodução e deslizamentos de sentidos ao longo do processamento histórico, isso porque na sociedade sempre há resistências que nos mostram a particularidade de lutas de deslocamento ideológico (PÊCHEUX, 2009), como diversos movimentos populares que insistem na extenuação de uma conservação social. Com efeito, compreendemos a instituição escolar como um espaço múltiplo, com coerções, resistências e contradições que circulam, hibridizam, propagam e materializam dialeticamente sentidos e práticas sociais.

Por esse quadro teórico, queremos, então, destacar dois pontos nodais para nossa análise: I. sobre a imbricação da contemporaneidade nas relações entre o discurso urbano, o social e o escolar; e II. sobre a interpretação escolar que se produz por esta imbricação, enquanto um lugar antropológico.

\section{Sobre a imbricação da contemporaneidade nas relações entre o discurso urbano, o social e o escolar}

Convém esclarecer o que estamos chamando de "urbano", aqui compreendido como um discurso da Cidade emergente de uma forma de expressão hibridizada pelas correntes socioculturais ao modo de pensar, sistematizar e agir nas práticas sociais. Ao enfatizar esse discurso, julgamos ser possível analisar os movimentos da discursividade sócio-histórica, assim como as relações entre o conhecimento científico (o citadino) e o cotidiano. Ele possibilita trabalhar com as significações remanescentes e emergentes do que é dito dentro e fora da escola, do que circula pelas linguagens organizadas e pelas linguagens desorganizadas social e historicamente.

Segundo Orlandi (2004), na Cidade existe formulações, também chamadas fulgurações (manifestações repentinas de inspiração), que estampam as narrativas dos sujeitos e produzem o discurso urbano. São desestabilizações do discurso ordinário que desorganizam as falas e tornam possíveis outras palavras, sentidos e sensações.

O discurso que atravessa o espaço escolar, como "o rap, a poesia urbana, a música, os grafitos, pichações, inscrições, outdoors, painéis, rodas de conversa, vendedores de coisa-alguma" (ORLANDI, 
2004, p. 31), sobrepõe o social na Escola. São discursos que se interpenetram e nos apontam como os sujeitos lá se organizam ao levarem as referências e vivências do mundo extraescolar. Assim, o urbano textualiza-se na Escola, atravessando o mundo dos estudantes por diferentes modalidades. Trata-se de um percurso que desorganiza as falas normativas-científicas pela narratividade urbana a qual "tem vários pontos de materialização. Moventes. Fulgurações. Materialidade dispersa. E é nas suas relações que podemos compreender esses seus sentidos” (ORLANDI, 2004, p. 31).

Nessa compreensão, as palavras, os gestos, as expressões, entre outros, que fazem parte dos dizeres urbanos dos sujeitos, não podem ser simplesmente desconectados pela Escola, merecem ser trabalhados e problematizados, a fim de que o processo de ensino seja significativo para aqueles que lá participam. Como afirma Orlandi (2004, p. 34, grifos da autora), “quando o espaço é silenciado o espaço responde significativamente. E nos faz, pela compreensão da cidade em suas formas de narratividade, pensar a des-transformação, o trocadilho como forma, a des-interpretação, como gesto". Portanto, assinalamos que os sentidos socioculturais, reformulados e colocados em circulação pelos sujeitos, não devem ser ignorados, mas significados pela Escola, contextualizados e mobilizados para emergência do aprendizado. Conforme esclarece Orlandi (2004, p. 36):

[...] a narratividade urbana enquanto fala que desorganiza, é um modo discursivo de trabalhar a espessura semântica da cidade, atravessar o urbano saturado e flagrar o real da cidade se significando em clarões, relâmpagos, luminosidades que não duram senão o tempo de um flash, de uma mirada, de um lembrete. Fulgurações. Mas que ficam na retina produzindo seus efeitos.

Dessa maneira, a narratividade urbana, que fulgura ao expor a organização e desorganização do social, permite-nos compreender o lugar do urbano e da ruptura com o politicamente instalado no contexto escolar. Para todos os efeitos, demonstra que a comunidade escolar se adapta, reinventa e produz novos significados socioculturais, o que nos incentiva a olhar a Escola como um ambiente mutável onde permeia a diversidade e a unidade do social. Um local de compreensão e incompreensão da socialização, nela circulam gestos e dizeres que visam a "incidência de novos processos de significação que perturbam ao mesmo tempo a ordem do discurso e a organização social” (ORLANDI, 2004, p. 63). Destacamos, assim, que "o conhecimento desses processos contribui para a melhor compreensão do que tem sido tratado sob o nome genérico de 'conflito social'” (ORLANDI, 2004, p. 63).

Há conflito social porque há diversidade, rupturas simbólicas, sobreposições de culturas e interesses de classes. Significa que os sujeitos não precisam estar no urbano (fora da Escola), porque o 
urbano já está lá, nas formações ideológicas. Ou seja, ele é preconstruído, é memória discursiva, é rede de formações discursivas que refletem a relação dos sujeitos com o conhecimento. $\mathrm{O}$ que se torna indispensável é aprender a se relacionar com o urbano para compreender a Escola na sua contemporaneidade, ou como diz Orlandi (2004, p. 152):

A Escola é um dos lugares - daí lugar de interpretação - em que a forma-sujeitohistórica que é a nossa (a capitalista, de um sujeito com direitos e deveres) se configura como forma sujeito urbana: o adulto, letrado, cristão, é urbano como projeto. Esse é o imaginário recorrente da civilização ocidental. Por que a Escola adquire toda essa importância? Por que esse sujeito da escrita, o sujeito do conhecimento? Não há urbanidade moderna sem escrita. Não há Estado sem Ciência. E a escrita se aprende na Escola. Eis a articulação de base: Estado/Ciência/Escrita. E está feita a modernidade.

Na relação Estado-Ciência-Escrita, o conhecimento é fugaz e perspicaz, é ao mesmo tempo o “outro" e o "mesmo" que a Escola precisa negociar. Porém, ao fazer a conversão do conhecimento recusado para o conhecimento legitimado pelos grupos de poder, ela apaga a luta ideológica que se constrói dentro e fora da sala de aula, entre os sujeitos, entre a estrutura e o acontecimento, entre o sistema e a sociedade. Nas palavras de Orlandi (2004, p. 152-153):

[...] a relação da Escola é precipuamente a relação com o conhecimento, este sendo considerado como modo de integração social. É este objetivo, com este móvel, que queremos pôr em dúvida quando pensamos a Escola na cidade. Nesse sentido, o colocar-se a Escola em seu meio simbólico específico que é a cidade nos dá um observatório do político e do social que não seria possível se não houvesse a explicitação desse meio, o urbano.

Por conta disso, é indiscutível dizer que o urbano faz parte da Escola, pois, já está posto, é impossível recusá-lo na contemporaneidade. O que urge é aprender a lidar com ele, saber viver com uma nova sociabilidade que conta com diferentes formas de pensar, de agir, de construir interpretações, de exteriorizá-las pelo universo amplo de linguagens. Uma vez que, pelo imaginário, estabilizador de sentidos e cristalizador da história, "a Escola, tal como se encontra, entra no sentido de reforçar a verticalização das relações de racionalidade, o conhecimento, junto à escrita, forma relações, a racionalidade, formando o núcleo da ação pedagógica" (ORLANDI, 2004. p. 153).

\section{Sobre a interpretação da contemporaneidade na Escola, enquanto um lugar e um} não lugar antropológico.

Marc Augé (1997) parte do pressuposto de que as interferências humanas, o desenvolvimento industrial, o crescimento e a mobilidade urbana e social, causaram impactos sobre o cenário da 
contemporaneidade. Para o autor, em oposição à modernidade, existe uma supermodernidade, que “corresponde a uma aceleração da História, a um encolhimento do espaço e uma individualização das referências que subvertem os processos cumulativos da modernidade” (AUGÉ 1997, p. 170). Por certo, a supermodernidade é tratada pelo funcionamento aguçado do capitalismo e que proporcionou particularidades sociais enraizadas na rapidez que ocorrem os movimentos históricos, no acesso aos espaços sociais e ao consumismo.

Desse modo, a contemporaneidade perfaz-se pelo entrelaçamento de discursos modernos e supermodernos que constituem a realidade dos sujeitos. Há novos mundos que expressam a relação dos indivíduos com os processos simbólicos (AUGÉ, 1997). Além do binômio modernidade/supermodernidade, Augé (1997, p. 169) propõe o binômio lugar e não-lugar antropológico, para discutir a relação simbólica do mundo contemporâneo, sendo que:

O lugar será definido como identitário (no sentido que um certo número de indivíduos podem se reconhecer nele e definir-se através dele), relacional (no sentido que um certo número de indivíduos, os mesmos, podem ver aí a relação que os une uns aos outros) e histórico (no sentido que os ocupantes do lugar podem encontrar nele os rastros diversos de uma implantação antiga, o sinal de filiação). Dessa forma, o lugar é simbólico triplamente (no sentido que o símbolo estabelece uma relação de complementaridade entre dois seres ou duas realidades): ele simboliza a relação de cada um dos seus ocupantes consigo mesmo, com os outros ocupantes e com a história comum.

No prisma antropológico, a panaceia de certos efeitos da contemporaneidade também pode ser ilustrada por espaços em que há distanciamento com aqueles que os frequentam, com aqueles que passam por eles na busca de um reconhecimento silenciado, conforme aponta Augé (1997, p. 169):

Um espaço no qual nem a identidade, nem a relação e nem a história sejam simbolizados será definido como um não lugar (non-lieu), mas essa definição pode ser ampliada a um espaço empírico preciso ou representação que os que lá se encontram fazem desse espaço. O que é um lugar para alguns pode ser um não-lugar para outros e inversamente. Um aeroporto, por exemplo, não tem o mesmo status na visão do passageiro que por ele passa na visão de quem nele trabalha todos os dias.

Nos não-lugares se joga com a busca do outro, em um espaço de passagem daquilo que se torna provisório para a supermodernidade. Supõe a existência de espaços preenchidos simbolicamente, mas humanamente esvaziados de sociabilidade. As noções de lugar e não lugar, portanto, representam espaços indissociavelmente simbólicos e empiricamente limítrofes, tais quais se encontram no mundo 
contemporâneo pela crise da alteridade, pela presença do outro-ausente, pelos estereótipos, pela linguagem urbana e cultural.

Há não lugar em todo lugar e em todos os não lugares os lugares podem se recompor. Podemos dizer isso de outro modo: lugares e não lugares correspondem aos espaços muito concretos, mas também às atitudes, a posturas, à relação que os indivíduos entretêm com os espaços onde elas vivem ou que percorrem. (AUGÉ, 1999, p. 145).

Nessa perspectiva, a supermodernidade é responsável pela expansão exacerbada dos nãolugares, pois ela produz espaços que não garantem vínculos com a memória identitária, relacional e histórica, mas que são indispensáveis para a garantia da concretude e simbolismo do mundo contemporâneo. $\mathrm{Na}$ medida em que todo não-lugar fica "prometido à individualidade solitária, à passagem, ao provisório e ao efêmero, propõe ao antropólogo, como aos outros, um objeto novo cujas dimensões inéditas convém calcular antes de se perguntar a que olhar ele está sujeito" (AUGÉ, 2012, p. 74). Ainda devemos considerar o fato de que os não-lugares inexistem de forma pura, isso porque retomam neles os lugares, pela invenção do cotidiano e pela historicidade que transita na contemporaneidade entre o mundo moderno e o supermoderno. Como escreve Augé (2012, p. 74):

O lugar e o não lugar são, antes, polaridades fugidias: o primeiro nunca é completamente apagado e o segundo nunca se realiza totalmente - palimpsestos em que se reinscreve, sem cessar, o jogo embaralhado da identidade e da relação. Os não lugares, contudo, são a medida da época; medida quantificável e que se poderia tomar somando, mediante algumas conversões entre superfície, volume e distância, as vias aéreas, ferroviárias, rodoviárias e os domicílios móveis considerados "meios de transporte" (aviões, trens, ônibus), os aeroportos, as estações e as estações aeroespaciais, as grandes cadeias de hotéis, os parques de lazer; e as grandes superfícies de distribuição, a meada complexa, enfim redes a cabo ou sem fio, que mobilizam o espaço extraterrestre para uma comunicação tão estranha que muitas vezes só põe o indivíduo em contato com uma outra imagem de si mesmo.

Nas condições instaladas pelos não lugares, os indivíduos não interagem com pessoas empíricas, nem pelas conivências da linguagem social, mas com textos morais e institucionais, e, assim, interagem pelas “injunções, dos conselhos, dos comentários, das 'mensagens' transmitidas pelos inúmeros 'suportes' (painéis, telas, cartazes) que são parte integrante da paisagem contemporânea" (AUGÉ, 2012, p. 95).

Tal que, os não lugares não operam uma integração sociocultural entre os indivíduos, mas autoriza a passagem deles, na temporalidade de um percurso, "o espaço do não lugar, não cria nem identidade singular nem relação, mas sim solidão e similitude" (AUGÉ, 2012, p.95). Portanto, ao usuário há uma relação contratual, um modo de uso do não lugar que o torna semelhante aos outros, ou 
seja, por exemplo, pela "passagem que ele comprou, o cartão que ele deve apresentar no pedágio, ou mesmo o carrinho que empurra nos corredores do supermercado são a marca mais ou menos desse contrato" (AUGÉ, 2012, p. 93-94).

Como ressalta Augé (2012), na realidade do mundo de hoje, as possibilidades de um não-lugar nunca está ausente de um lugar e vice-versa. À volta, a retomada, o itinerário demonstra que eles se engendram conjuntamente. Os lugares e não lugares "se opõem (ou se atraem), como as palavras e as noções que permitem descrevê-las. Porém, as palavras em moda - as que não tinham direito à existência há uns 30 anos - são as do não lugar" (AUGÉ, 2012, p. 98). A partir dessas noções de lugar e não-lugar, instala-se a contradição, haja vista que o espaço da supermodernidade:

[...] só trata com indivíduos (clientes, passageiros, usuários, ouvintes), mas eles só são identificados, socializados e localizados (nome, profissão, local de nascimento, endereço) na entrada ou na saída. Se os não lugares são os espaços da supermodernidade, é preciso explicar esse paradoxo: o jogo social aparece acontecer mais noutros lugares do que nos postos avançados da contemporaneidade. (AUGÉ, 2012, p.102).

Nesse ínterim, os sentidos produzidos pela noção de lugar e de não-lugar nos valem para esclarecer a constituição do espaço escolar na contemporaneidade. Antropologia e discurso trazem possibilidades de analisar criticamente o urbano, o social e o ensino que se produz na Escola. Procuramos, portanto, compreendê-la como um lugar antropológico e também de problematizá-la enquanto um não-lugar. Tratar a escola como um não-lugar é uma hipótese cara, mas que nos parece razoável, devido ao contexto urbano, ao nosso trabalho com linguagens e relações que ocorrem aquém e além do espaço escolar. Mas que almejamos que ela possa ser revista como um espaço articulador da urbanidade, ciência, sociedade, e de imbricação de novos mundos e da formulação e circulação da discursividade que constituem a sua relação histórico-social.

\section{Metodologia de Produção da Pesquisa}

O presente artigo resulta de uma pesquisa de doutorado que investiga a leitura na formação docente. Os diários aqui analisados foram escritos pelos licenciandos ao longo do estágio supervisionado da Prática de Docência ministrada pelos autores no curso de Ciências Biológicas da Universidade Federal do Paraná (UFPR). 
A turma, constituída por nove estudantes, foi convidada a participar da pesquisa no início do ano letivo, tendo, para isso, assinado um termo de Consentimento Livre e Esclarecido, autorizando o uso de todo material escrito por eles como diários, questionários e planos de ensino.

A disciplina em questão é ofertada no quinto e último ano do Curso, desenvolvida em 210 horas (anual), distribuídas em 60 horas teóricas na universidade e 150 de estágio na Escola. Nas aulas teóricas, promovemos leitura e discussão de textos, em que foram tratados temas como: relações entre saber e aprender; mediação didática; escola e o processo de reprodução social e cultural; práxis docente; epistemologia da ciência; enfoques histórico e social dos conteúdos; livro didático; diferentes linguagens no ensino de ciências; Educação de Jovens e Adultos (EJA).

Já no estágio, a turma dividiu-se em duas escolas, sendo uma na região metropolitana e outra próxima à universidade, situada na região central de Curitiba. Os estudantes realizaram nesse período: observações e análise sobre o espaço físico, o projeto pedagógico, os planos de ensino, as aulas ministradas pelos professores de ciências e biologia; entrevistas com professores, coordenação pedagógica e alunos; a prática docente nas modalidades de Ensino Fundamental (EF), Ensino Médio (EM) e EJA.

As análises dessas atividades foram realizadas com base nas teorias estudadas e descritas pelos estagiários em diários de campo. A nosso ver, a escrita em diário supõe cumplicidade dos estudantes com a subjetividade da docência, pois as anotações e relatos estão mais próximos da realidade observada no contexto escolar. Nas aulas teóricas, os diários foram constantemente discutidos e reconstruídos pelos estagiários, sendo recolhido para avaliação apenas no final do ano letivo. Isso porque acreditamos em uma historicidade da formação docente em que os aspectos pedagógicos podem permanecer, mas também deslocar e transformar-se quando concebidos por um prisma discursivo e praxiológico.

De posse do referencial teórico acima apresentado buscamos compreender como os mecanismos ideológicos que se confrontam no espaço escolar emergem nas descrições dos Licenciandos em situação de estágio. Para tanto, escolhemos os diários que descrevem sobre a Escola central da cidade de Curitiba. 


\section{A Escola como um lugar (e um não-lugar) de interpretação da contemporaneidade}

Apresentamos aqui alguns recortes das análises que os estagiários produziram sobre a Escola, campo de estágio, que se localiza em uma região central, próxima da parada de diversas linhas de ônibus e contêm diferentes perfis de alunos que, de maneira geral, vêm de outras regiões da cidade, principalmente da área metropolitana, sendo o alunado constituído, portanto, de diferentes lugares e classes sociais. Há relatos de professores, do pedagogo e da direção da escola sobre desafios e dificuldades para o trabalho docente, envolvendo a condição socioeconômica, repetência, evasão escolar e indisciplina de alunos, além de casos de promiscuidade, drogas e violência em torno do perímetro escolar que chegam até os alunos.

Nossas análises partem a princípio do Ensino Fundamental (EF) e Médio (EM) e, em seguida, a modalidade da Educação de Jovens e Adultos (EJA).

Nos registros dos estagiários que acompanharam as aulas no EF e EM, de um modo geral, há uma ideia de "crise da noção de lugar antropológico" para abordar a Escola. Uma vez que, em diversos momentos, são apontadas certas dificuldades: na construção identitária da relação aluno-professor; na relatividade da construção simbólica, já que os alunos que frequentam a Escola (no centro da capital) são de outro contexto social-urbano (da região periférica); na crise histórica, haja vista que não são apontadas regularidades simbólicas, mas sim diversidade, instabilidade social e urbana que constitui este espaço.

Nessa perspectiva, alguns pontos destacados no diário do Estagiário 1 problematizam uma série de dificuldades encontradas e que interferiram na propositura de uma atividade com leitura e escrita no oitavo ano do EF:

Quando fomos lecionar, isso ainda no primeiro semestre, aplicamos uma atividade sobre alimentação onde os alunos deveriam ler sobre a cultura alimentar de quatro regiões diferentes. Conversando com meus colegas que também estavam participando dessa aula, percebi que o momento da leitura foi problemática, pois por não terem nenhum hábito de ler a atividade quase não deu certo e precisávamos da participação deles no andamento da aula. Ainda neste dia, pedi aos alunos para escreverem o que eles acharam da atividade toda e o que eles me deram foram parágrafos com muitos erros ortográficos, algumas frases sem sentido, uma escrita imitando a oralidade e conversas virtuais onde não há preocupação com a norma culta. (Estagiário 1, grifos nosso).

O relato aponta para um descompasso entre a linguagem escrita urbana e linguagem escolar, o que vai ao encontro do que diz Orlandi (2004), no qual vemos um discurso urbano circulando, por 
sentidos deslegitimados e desconhecidos pela Escola, mas que se entrecruzam no ato de ensinar. A nãointerpretação escolar da linguagem urbana, enquanto linguagem constituinte dos sujeitos, é deflagrada, principalmente, quando o estagiário reforça que a escrita dos estudantes desobedecia à norma culta (ao discurso ordinário) e fugia das expectativas do que era esperado para aquela atividade, ou seja, mostra dois processos ideológicos que se constroem no espaço escolar: o institucionalizado e o urbano.

Cabe ressaltar, assim, o grande desafio da contemporaneidade no qual a Escola precisa trabalhar-interpretar-preocupar para compreender os discursos circulantes, a fim de atingir uma linguagem articulada e conectada com os interesses dos alunos, capaz de mobilizar um conhecimento científico, aliado a essas relações sociais instaladas fora e dentro da escola, sem perder sua configuração histórico-social. Não propomos substituir uma linguagem por outra, mas em emergi-las, para tomar conhecimento de como podem ser trabalhadas como práticas significantes dos sujeitos.

No diário de campo da Estagiária 2, observamos uma remissão da Escola em enfrentar a cultura dos alunos (o urbano), da qual urge um apelo de cidadania para a questão do sistema educacional.

Não foi observado respeito à diversidade e a cultura, mas a culpa não é dos estudantes deste ou aquele colégio. A problemática é bem mais profunda, trata-se da inserção social/cultural e o contexto social moderno. O que temos a oferecer no papel de professores é tentar criar nessas crianças a vontade de viver em um mundo melhor e para isso se tornar pessoas melhores dia a dia na vivência escolar. Respeitando e aceitando o próximo. Acredito que são nos valores, citados na discussão teórica do Projeto Político Pedagógico da escola, que devemos aprender a ensinar. Temos que deixar de enxergar os alunos de forma verticalizada. Saber que temos muito que aprender com estes estudantes. E que na verdade, se a educação brasileira se encontra tão caótica é porque estes estudantes estão pedindo socorro e precisam da nossa ajuda para a mudança e para esperança de acreditar em um futuro melhor. [...] $\mathbf{O}$ professor deve ter lucidez para saber até onde ir, o que deve saber em detalhes e o que precisa apenas apresentar ao aluno. $O$ professor carece de atualização científica e metodológica, a forma com que ele chegará a isso vai depender da condição social e econômica da escola. Desta forma compreendemos que as vivências deste trabalho tem mais a ver com a atitude que teremos como professores do que a compreensão da teoria dos conteúdos passados para os alunos em sala de aula. $O$ importante é ensinar ao aluno como ser cidadão e fazer ele buscar dentro de si o significado do aprendizado dos conteúdos ministrados em sala de aula. (Estagiária 2, grifos nosso).

A Estagiária 2 discute os efeitos da contemporaneidade no contexto observado. Há um pressuposto de que é necessário perturbar a perspectiva tradicional que ronda o espaço escolar, em suas acepções identitárias, relacionais e históricas. Suas angústias e preocupações anseiam para que, antes de qualquer coisa, a Escola possa ser (re)vista como lugar construtor de cidadania. Seu relato nos indica uma acepção de cidadania, conforme destaca Orlandi (2004), que se dá no cruzamento do político com 
o simbólico, ou seja, em como o social se significa no sujeito nos diferentes sentidos da cidade governada pelo Estado. A estudante ainda destaca a importância de se despertar uma "mobilização interna" nos alunos pelo conhecimento para que possam desenvolvê-lo nas relações sociais. Reflete ainda um sentido para que os professores ascendam o desejo de o aluno aprender, desencadeando uma necessária relação com o saber.

A partir de uma análise e comparação de aulas de ciências e biologia, o Estagiário 3 faz alguns registros sobre a Escola, que a personaliza como uma instituição disciplinadora e controladora das relações sociais pelo poder:

É nítida a diferença na posição em sala de aula dos alunos do E.M. para os alunos do E.F. Os do E.M. já são menos interessados, curiosos e participativos, mais comportados e indiferentes ao conteúdo. As aulas no E.F. decorriam com muita bagunça, conversa, brincadeiras, entretanto, mesmo os alunos que participavam da bagunça por vezes o professor conseguia chamar e cativar em seu ensino, no E.M. os alunos mais indiferentes não participavam de maneira alguma da aula, o que fazia com que muitas vezes a professora não tivesse nenhuma tentativa de resposta para suas perguntas, tornando a aula monótona. [...] Nesse ambiente, a escola funciona como uma instituição reprodutora de conhecimento e do modelo de sociedade atual. Mesmo experimentando raros momentos em que o professor constrói o conhecimento em diálogo com os alunos, me parece que esse diálogo é feito sem o devido planejamento e de maneira incipiente [...] ignorando os saberes populares dos alunos [...] Os saberes escolares são transmitidos para os alunos de maneira acrítica sem um estímulo por parte dos educadores para que os alunos tenham curiosidade maior, sendo estes apenas receptáculos para o conteúdo a ser doado pelo professor, que acaba por agir, consciente ou não, em prol das classes dominantes da perpetuação das contradições sociais. (Estagiário 3, grifos nosso).

A Escola é mostrada como o lugar da indisciplina, do (des)controle e da reprodução do conhecimento cultural e social. Nos registros do estudante a progressiva falta de diálogo e participação dos alunos, evidencia uma castração da "vivacidade" dos alunos, que começa no EF, gerando uma resistência à interpretação da ordem social praticada na Escola e resulta em um efeito de "passividade" do alunado e desgaste da atividade professoral, observado no EM.

A desconectividade ensino-interação ressalta uma das fragilidades da Escola no contexto atual, que reforça seu caráter de transmissão do conhecimento e a não busca pela interpretação dos saberes populares (urbanos) dos alunos. Fato que leva o Estagiário a considerá-la um instrumento de reprodução das condições ideológicas sociais.

Nessas circunstâncias, a importância da sociabilidade entre o escolar e o urbano significa “não guetificar as relações, porque não somos animais em interação, somos sujeitos e, enquanto sujeitos, 
seres que significam na sociedade e na história. É preciso impedir com empenho a segregação" (ORLANDI, 2004, p. 89). Além do mais, segundo Orlandi (2004, p. 89), quando "se destituem os sujeitos dessa sua condição social e histórica, que é a sociabilidade, certamente se o faz em prejuízo do próprio homem. Em vez de rarefazer, é preciso reafirmar nossa capacidade. Os fechamentos diminuem essa nossa capacidade".

O descontentamento dos alunos na sociabilidade escolar também é evidenciado no diário da Estagiária 4:

Os alunos entrevistados demonstraram uma frustação e descontentamento com as regras de comportamento estabelecidas pela direção da escola. Muitas coisas como a obrigatoriedade da utilização do uniforme, por exemplo, são vistas de maneira negativa pelos alunos. Eles comentam que são mandados para a direção e levam ocorrência por "qualquer coisinha" ou até são encaminhados para o conselho tutelar, Na visão dos alunos, a escola não quer resolver os problemas de professoraluno em sala de aula e é na "autoridade" que a escola tenta lidar com os alunos. Isto é, eles gostariam que os professores conversassem com eles diretamente e não ficassem repassando o caso da indisciplina para a direção ou pedagoga, pois acreditam que podem solucionar os problemas diretamente com o professor. [...] Ficam frustrados, pois mal existe um representante de sala e não tem nenhuma movimentação de grêmio estudantil ou mobilização dos estudantes. Segundo os alunos, eles são "podados" e pouco incentivados a realizar este tipo de agrupamento. Eles se queixam que não existem atividades diferenciadas, apenas aulas expositivas. [...] É preciso manter vivo o interesse, o gosto, o prazer pela aprendizagem, que tantas vezes são substituídos por práticas que, ao adquirirem o caráter de obrigatoriedade, de repetição pura e simples ou pelo fato de não fazerem o menor sentido, fazem brotar em nossos alunos o gosto e mais a desmotivação, menos o prazer e mais o desinteresse pelo que lhe é proposto. (Estagiária 4, grifos nosso).

Manifesta-se no posicionamento da Estagiária 4 uma discordância da situação instalada na Escola concebida como castradora de lideranças e desconstrutora de uma relação dialógica entre os estudantes e o conhecimento. As representações ideológicas e simbólicas (fulgurações), estampadas nas narratividades urbanas dos estudantes são diminuídas, pela coação das autoridades escolares, na repressão da desobediência de regras e que sufocam alguns bendizeres sobre o processo de ensinar e aprender na instituição em questão.

Nessa complexidade, segundo a estagiária, é preciso buscar alternativas para a relação (repressão) entre o social e o urbano, o que implica gerar nos estudantes o gosto pelo aprendizado, uma fluente relação com o saber, que torne o ensino motivador e gere interesse no que é ensinado. Supõe, portanto, que no contexto da contemporaneidade-discursividade escolar cabe aos professores 
incentivar, construir, criticar e mobilizar os conhecimentos com base nas disposições dos alunos em aprender.

Até este momento, destacamos alguns pontos principais dos diários que refletem a noção e uma crise de a Escola como um lugar antropológico (em suma, identitário, relacional e histórico). Mas, em outros diários de estagiários que acompanharam as aulas da EJA constatamos uma clarividência de a Escola ser vista por uma noção de não-lugar (lugar não identitário, não relacional e não histórico).

A modalidade EJA é ofertada no período noturno, sendo que a maioria dos alunos trabalha durante o dia. Muitas vezes, os estagiários escrevem que foram para Escola, mas não havia alunos, não havia aula e quando havia prevalecia pouca sociabilidade. Os jovens e adultos interagiam com o material didático, respondiam suas tarefas sem muita interação com o professor-tutor, que apenas auxiliava com instruções previstas e esperadas.

Para os estagiários, devido à localização sócio-urbana, a Escola acaba sendo um espaço de passagem, de travessia do trabalho para a casa, as aulas acabam sendo sintetizadas, pois os alunos precisam sair a tempo (antes das últimas aulas), para encontrar um ônibus para voltar para casa. Nessas condições, o estágio tornava-se uma tarefa espinhosa para analisar os pontos destacados por outros colegas sobre a mesma Escola, como bagunça, narratividades, interação, indisciplina, fulgurações, tempo, linguagem etc., pois nem essas manifestações se expressavam.

Levando em conta que a realidade escolar passava longe dos fundamentos teórico-práticos defendidos nos documentos oficiais, visto que a maior preocupação dos jovens e adultos era alicerçada por um "contrato" estipulado pelo mercado de trabalho, a EJA torna-se lugar de solidão, de travessia para outro lugar e, portanto, a nosso ver, um não lugar produzido pela supermodernidade.

Nessa direção, o Estagiário 5 aborda a não-interpretação escolar da emergência das representações socioculturais, o que seria muito pertinente, pois os estudantes carregam diferentes histórias de vida que pesam frente ao ensinar e aprender ciências:

É necessário compreender a diversidade dos sujeitos da EJA de modo que jovens e adultos possam, de fato, fazer parte da escola. Muitos deles apresentam história de fracasso, de não aprendizado, de frustrações, por isso, não é possível repetir modelos e manter abordagens que comprometam seu desenvolvimento. Ler e escrever são práticas indispensáveis às sociedades em que a cultura escrita regula a vida social, o que quer que jovens e adultos aprendam ao longo da vida num diálogo constante com seus saberes que não podem ser ignorados. A EJA representa suas particularidades e, é nesse contexto, que se percebe a necessidade de preparar professores para lidar com as situações recorrentes, de trabalhar conhecimentos e saberes técnicos-metodológicos que contribuam para uma prática educativa que 
observe a diversidade de gênero, geração, etnia e diferentes opções religiosas, ideológicas, políticas em situações de inovação educativa de trabalho. (Estagiário 5, grifos nosso).

Segundo o Estagiário 5, para compreender a Escola, antes, é necessário compreender como os alunos chegaram (voltaram) até ela, quais os processos de lutas e resistências eles enfrentaram para retomar seus estudos. Importa compreender a história (a historicidade) desses "usuários" do sistema público de ensino, o que passa por individualizar o plural, simplificar o complexo, subvertendo os valores da modernidade nas condições pressionadas pela contemporaneidade.

O estudante também aponta a importância da capacitação de professores para essa modalidade de ensino. Defende, sobretudo, a pluralidade cultural, histórica e social que preenche a Escola e que requer professores atentos às medidas e estratégias de ensinar a ciência. Prevalece, em suas palavras, a necessidade da criação de vínculos entre os jovens e adultos (usuários) e a Escola (não-lugar), enquanto produtora de uma sociabilidade imaginária, a fim de que as referências, as histórias e as memórias desses sujeitos possam ser significativamente trabalhadas no processo de aprendizagem.

O diário de campo do Estagiário 6 aponta, também, uma série de reflexões produzidas durante o acompanhando das aulas de biologia em turmas da EJA:

A escola deve contribuir para a formação de cidadãos mais completos, capazes de resolverem seus problemas e os problemas que afligem a sua comunidade. Talvez seja necessária uma abordagem diferenciada na EJA, que possa aproveitar o fato de seus integrantes serem pessoas com certa convivência e um nível de responsabilidade diferente dos alunos regulares, buscando trazer novas maneiras de ensino que aproveitem melhor o curto tempo que eles têm e venha agregar valores e conhecimento que eles possam utilizar no dia a dia em suas vidas. Explorar os problemas que afligem a população adulta, sob o prisma da Biologia e buscar construir nesses alunos ideias holísticas e versáteis, trabalhar também o lado cultural e aliar disciplinas como artes, história, geografia ou matemática para ajudar a entender os processos biológicos. Fica claro que as estratégias e diretrizes de educação para a EJA não estão sendo efetivas na escola e que os alunos não estão tendo proveito das oportunidades que podem ter voltando a estudar. Da forma como é feito o manejo das escolas, hoje os alunos vêm buscar a formação na EJA apenas para preencher uma lacuna que a sociedade cobra, não importando se estão aprendendo algo ou não, no final, o certificado de conclusão é o troféu que buscam e não a melhoria de sua condição através do conhecimento. (Estagiário 6, grifos nosso).

Como percebemos, o Estagiário 6 radicaliza uma crítica à forma como o ensino da EJA é conduzido na Escola. Em meio às limitações e às possibilidades observadas, ele aponta que a Escola precisa rever seus conceitos do que é praticado nessa modalidade de ensino, bem como procurar uma abordagem diferencial, tendo em vista o público acolhido cotidianamente. Em suma, ela precisa 
identificá-los. Necessita de uma interligação dos conhecimentos por uma perspectiva multidisciplinar que ancore os conhecimentos dos alunos à realidade cotidiana. Sem essa concepção, conforme ele escreve, a Escola não passa de uma "fábrica de diplomas" que valem como "moedas de troca" para o mercado de trabalho, visto que se ignora uma interpretação reflexiva, cidadã, consciente dos meios de produção que ela reproduz e transforma.

Temos, portanto, a Escola, enquanto um não-lugar, ou ainda, o lugar da falta, do outro-ausente, da crise de alteridade na formação dos alunos-cidadãos. Desse modo, o estagiário propõe - para a coexistência de individualidades em um dado período de tempo - uma visão holística, que o não-lugar não é capaz de ofertar, para que somente assim o espaço escolar não seja vazio e, sobretudo, o conhecimento não se torne fugaz (mercadoria), mas ancore significados nas memórias discursivas dos alunos, na realidade social e urbana.

Resta dizer que nos diários observamos formas de pensar a Escola em um contexto problemático, diverso e desafiador de processos de ensino que podem (ou não) ser mobilizadores de uma práxis docente, como um lugar (ou não lugar) de interpretação social e urbana do mundo contemporâneo interligado pelos novos mundos que o constituem. Novos mundos nos quais "não importa a que ordem na realidade pertençam, têm em comum o paradoxo que os define: exprimem, ao mesmo tempo, a singularidade que os constitui e a universalidade que os relativiza" (AUGÉ, 1997, p. 143).

Nessa relação de sentidos entre a interpretação escolar e a contemporaneidade são diversos pontos que ilustram o embate com o urbano, a luta e a resistência de um contexto de ensino escolar(izado). Há choque entre discursos, ideologias e políticas instaladas dentro e fora da Escola; há possibilidades e limites de transformação das situações encontradas que dependerão da formação inicial e continuada de professores para enfrentar essa realidade.

\section{Reflexões para uma consideração provisória}

Este estudo pretendeu diagnosticar algumas perspectivas para se pensar a Escola no contexto da contemporaneidade. Não temos, certamente, soluções e respostas para a maioria dos problemas e desafios levantados por esses estagiários. Antes, procuramos nesse contexto destacar alguns elementos que permitam entender o processo que se engendra ao conhecimento nos espaços escolares e extraescolares por diferentes re(1)ações sociais e urbanas. 
Comecemos por dizer que a Escola atual é resultado de discursos e ideologias circulantes na contemporaneidade, que geram diferentes interpretações pelos sujeitos que por ela passam. Não é nenhuma novidade dizer que o sistema escolar é hoje um lugar plural e singular, de debates e embates, de diálogos e monólogos, lutas e resistências etc., mas convenhamos que a reflexão se esvazia de perspectivas mais significativas se não situamos elementos sociológicos, históricos e ideológicos para abordar a amplitude de suas dimensões políticas e sociais.

Portanto, não cabe conceber a Escola de forma inflexível, prevista e verticalizada, pois as fragilidades, provisoriedades, horizontalidades, subjetividades, multiplicidades se entrecruzam nos sentidos (e sentimentos) dos sujeitos que a interpretam e que a veem oscilando como um lugar e um não lugar. Nessa ocasião, vimos que uma Escola aberta para sociedade, mas fechada para a realidade social, pode alienar o trabalho intelectual (o esforço, a reflexão, a crítica, a construção do pensamento etc.) dos sujeitos, pois desqualifica o trabalho intelectual de ensinar e aprender, assim como desqualifica a atividade de quem quer aprender para ensinar.

Dessa forma, urge pensar em uma educação predisposta a acolher o mesmo, o diferente, a transformação do conhecimento. Uma Escola que se abra, não para trazer o mundo até ela, mas para ela sair para o mundo, para que a ciência chegue até a sociedade, a realidade daqueles que carecem de conhecimento em lugares e não-lugares da vida social, em suma, implica na perspectiva discursiva "[...] em fazer a escola ir para rua" (ORLANDI, 2004, p. 152, grifo da autora).

Por nossas articulações teóricas, observamos que os estagiários apontam a Escola em meio a uma crise de lugar identitário, relacional e histórico. A controvérsia da suposição do lugar escolar se acentua ainda mais na EJA, em que os alunos se tornam usuários-clientes, o ensino torna-se um contrato-serviço, o conhecimento um cartão-produto, o aprendizado o consumo-gasto e a sala de aula um espaço provisório-passagem para o mercado-trabalho. Uma crise em que as noções de lugar e nãolugar coexistem no mesmo espaço ao mesmo tempo.

Nessa relação espaço-sujeito, ressaltamos a condição ideológica (a contradição) dos não lugares, já que a supermodernidade os aumenta quantitativamente, mas os diminui qualitativamente. Por conta disso, pensar o ensino nas situações analisadas requer a compreensão do espaço extraescolar, das diferentes formas de linguagens, daquilo que é produzido dentro e fora da Escola, em uma palavra: discursividades. Por isso, na produção do conhecimento escolar e na formação de professores, não podemos pensar em práticas, mas em práxis (ações históricas, dialógicas e dialéticas). Nesse sentido, o 
ensino deixa de ser repassado e propicia um encadeamento teórico-prático da atividade docente com os conhecimentos da ciência, do cotidiano, da Escola, da sociedade.

Os discursos dos estagiários mostram que não podemos pensar apenas a formação de professores no sentido de "formatar para gestar" conhecimento, para lidar com o mundo urbano da escrita, das tecnologias, das informações, das suposições; mas "formar para problematizar" o conhecimento, para incessantemente construir, desconstruir e reconstruir teorias, saberes e reflexões para a interpretação da Escola, para o ensino e para a realidade dos alunos.

Desse modo, julgamos que existem diferentes possibilidades de realizar uma formação praxiológica que podem ser mobilizadas na Universidade, que suscitem os conhecimentos da pluralidade e da unidade existentes no contexto escolar. Entre elas, as atividades de escuta dos licenciandos e aprofundamento de suas expressividades sobre a Escola, construindo dispositivos subjetivos e objetivos, particulares e plurais, conscientes e ideológicos, históricos e sociais e tantos outros que possam aproximá-los do aprender, do ensinar, e, sobretudo, a mobilizar os conhecimentos para além da sala de aula.

Considerar o aluno, sua linguagem, sua história e seus anseios, foi algo que aflorou nos discursos dos estagiários, como forma de desestabilizar o (dis)curso histórico, social e ideológico do qual a Escola faz parte e foi a partir destas percepções que procuramos encaminhar o Estágio.

\section{REFERÊNCIAS}

AUGÉ, Marc. Por uma antropologia dos mundos contemporâneos. Rio de Janeiro: Bertrand Brasil, 1997.

AUGÉ, Marc. O Sentido dos Outros: atualidade da antropologia. Petrópolis: Vozes, 1999.

AUGÉ, Marc. Não Lugares: uma introdução a uma antropologia da supermodernidade. 9. ed. Campinas: Papirus, 2012.

BOURDIEU, Pierre. Escritos de educação. 14. ed. Petrópolis: Vozes, 2013.

ORLANDI, Eni. Interpretação: autoria, leitura e efeitos do trabalho simbólico. Petrópolis, RJ: Vozes, 1996.

ORLANDI, Eni. A linguagem e seu funcionamento. 4. ed. Campinas, SP: Pontes, 2006.

ORLANDI, Eni. Cidade dos sentidos. Campinas, SP: Pontes, 2004. 
ORLANDI, Eni. Discurso em análise: sujeito, sentido e ideologia. 2. ed. Campinas, SP: Pontes, $2012 \mathrm{a}$. ORLANDI, Eni. Discurso e leitura. 9. ed. São Paulo: Cortez, 2012b.

ORLANDI, Eni. Análise de Discurso: princípios e procedimentos. 11. ed. Campinas, SP: Pontes, 2013. PÊCHEUX, Michel. Discurso: estrutura ou acontecimento. 3. ed. Campinas, SP: Pontes, 2002. PÊCHEUX, Michel. Semântica e Discurso: uma crítica à afirmação do óbvio. 4. ed. Campinas, SP: Editora da UNICAMP, 2009.

PÊCHEUX, Michel. Análise de Discurso: textos escolhidos por Eni Orlandi. 3. ed. Campinas, SP: Pontes, 2012. 
Discourse, ideology and teaching in contemporaneity: the school as a place (and non-place) of urban and social interpretation

\begin{abstract}
This study analyzes six diaries of internship produced by undergraduates of a Biological Sciences course, in which they describe observations made on a Public School, intending to observe how ideological mechanisms faced at school emerge in the descriptions of these undergraduates. In the approximation of the School to the City, we analyze the relationship between the world of education and the reality of the subjects through the Discourse Analysis, in particular the concepts of Ideology, Urban Discourse and anthropological concepts of Place (space of relationship between identity, relational and historical) and Non-Place (illustrated by the relationship of distance). We observed that the students pointed out the school as in crisis of identity, relational and historical place - crisis in which the notions of place and non-place coexist in the same space at the same time. We emphasize that in the production of school knowledge and teachers education, we cannot think of practice, but of praxis (historical, dialogical and dialectical actions), and is necessary considers the school as a multifaceted space that produces discourses and ideologies, where the temporariness, conflicts, crises, pluralities and ruptures are intersected.
\end{abstract}

Keywords: School. Interpretation. Teachers Education.

\section{Leandro Siqueira Palcha}

E-mail: leandropalcha@ufpr.br

Odisséa Boaventura de Oliveira

E-mail: odissea@terra.com.br
Discours, idéologie et éducation dans la société contemporaine: l'école comme un lieu (et non-lieu) de l'interprétation urbaine et sociale

\section{Résumé}

Cette étude analyse six carnets de terrain de stages écrits par des étudiants d'un cours en sciences biologiques, dans lequel ils décrivent les observations faites dans une école publique. Notre objectif est d'observer la manière dont les mécanismes idéologiques rencontrés à l'école apparaissent dans les descriptions de ces étudiants. Pour comparer l'école à la ville et pour analyser la relation entre le monde de l'éducation et la réalité des sujets nous utilisons le cadre théorique de l'Analyse du Discours, en particulier les concepts d'Idéologie, Discours Urbain et les concepts extraits de l'Anthropologie, comme Lieu (espace de caractère identitaire, relationnel et historique) et Non-Lieu (illustré par le rapport à la distance). Nous avons observé que les étudiants montrent l'école au milieu d'une crise de Lieu pour développer des relations d'identité et de vécu. Crise dans laquelle les notions de Lieu et Non-Lieu coexistent dans le même espace et en même temps. Nous soulignons que dans la production de connaissances scolaires et dans la formation des enseignants, nous ne pouvons pas considérer la pratique, mais la praxis (actions historiques, qui prennent en compte le dialogue et la dialectique). Et nous devons conçoit l'école comme un espace à multiples facettes, espace de production des discours et des idéologies, où le provisoire, les conflits, les pluralités, les crises et les ruptures se croisent

Mots-clés: École. Interprétation. Formation des Enseignants.

Enviado em: 2/4/2014

Aprovado em: 4/8/2015 